\section{Missed diagnosis of chronic inflammatory demyelinating polyneuropathy in a patient with cervical myelopathy due to ossification of posterior lon- gitudinal ligament.}

\author{
Min Cheol Chang \\ Department of Physical Medicine and \\ Rehabilitation, College of Medicine, \\ Yeungnam University, Taegu, \\ Republic of Korea
}

\begin{abstract}
In the current study, we report a missed diagnosis of combined chronic inflammatory demyelinating polyneuropathy (CIDP) in a patient with a cervical spinal cord lesion. At 3.5 months after the onset of symptoms, a 60-year-old female with mild motor weakness and significant weight loss underwent a surgical operation for decompression of the cervical spinal cord. However, her motor weakness was severely aggravated despite the surgical treatment, and she could not walk independently at 10 months after symptom onset. Based on the results of electrophysiological and cerebrospinal fluid tests, we diagnosed her with CIDP. Considering her medical history and the results of our evaluations, we think our patient's neurological symptoms before the surgical operation were attributed, at least in part, to CIDP. Our study shows that clinicians should consider the possibilities of other lesions in different areas even when patients have a definite lesion in the cervical spinal cord or cervical spine.
\end{abstract}

\section{Introduction}

Neurological symptoms, such as motor weakness and sensory disturbances, are caused by various disorders of the nervous system. In clinical practice, it is not easy to find a lesion causing a patient's neurological symptoms through only physical examination. Furthermore, occasionally more than two lesions in different areas of the nervous system can be overlapped.1-3 Additionally, in many cases, lesions in the nervous system are asymptomatic. ${ }^{4-7}$ Accordingly, thorough examination is necessary for finding the accurate pathology related to a patient's neurological symptoms. For the accurate diagnosis of neuro- logical disorders, several evaluation tools such as magnetic resonance imaging (MRI), computed tomography (CT), and ultrasound are being used. In particular, nerve conduction study (NCS) and electromyography (EMG) play a key role in the diagnosis of a peripheral nerve lesion and the assessment of its extent and severity. ${ }^{8}$

In the current study, we report a case of missed diagnosis of chronic inflammatory demyelinating polyneuropathy (CIDP), which is one of peripheral polyneuropathies, in a patient who underwent spinal decompression surgery due to cervical myelopathy induced by ossification of the posterior longitudinal ligament (OPLL). By reporting this missed diagnosis, we intend to emphasize the importance of thorough examination of the nervous system before confirming a diagnosis of a neurological disorder. In particular, we intend to show the necessity of NCS and EMG to rule out other combined disorders in peripheral nerves in patients with cervical spinal cord lesions.

\section{Case Report}

A 60-year-old female was referred to the rehabilitation department of a university hospital for progressive motor weakness and neuropathic pain in the upper and lower extremities. The patient provided informed consent for participation in the study. The study was approved by the local Institutional Review Board of our hospital. Her motor weakness initially manifested ten months prior, and her motor weakness started in the lower extremities prior to being in the upper extremities. She also presented with a tingling sensation and numbness in both upper and lower extremities. Three months after symptom onset, she went to the neurosurgery department of another university for progressive motor weakness and a tingling sensation at both upper and lower extremities. She was able to walk independently but with an observable mild wide-base gait. In addition, she reported weight loss of $10 \mathrm{~kg}$ during 2 months. In the physical examination, the patient presented with mild motor weakness (Medical Research Council [MRC]9: 4+/5) (Table 1) and mildly decreased tactile sensation in all extremities. CT and MRI showed OPLL at the level of C3-T1 and cervical spinal cord compression (Figure 1). In addition, on T2weighted images, high signal intensity was seen in the cervical spinal cord at the C5-6 disc space level (Figure 1). At that time, electrophysiological tests, including NCS and EMG, were not performed. At 3.5 months after symptom onset, the patient
Correspondence: Department of Physical Medicine and Rehabilitation, College of Medicine, Yeungnam University 317-1, Daemyungdong, Namku, Taegu, 705-717, Republic of Korea.

Tel.: 82.53.620.4682.

E-mail:wheel633@gmail.com

Key words: Chronic inflammatory demyelinating polyneuropathy; cervical myelopathy; electrophysiological study.

Conflict of interest: the authors declare no conflict of interest.

Funding: This work was supported by the National Research Foundation of

Korea (NRF) grant funded by the Korea government (MSIT)

(NRF-2017R1C1B5017714).

Received for publication: 25 March 2018

Revision received: 25 June 2018.

Accepted for publication: 3 July 2018.

This work is licensed under a Creative Commons Attribution NonCommercial 4.0 License (CC BY-NC 4.0).

(C) Copyright M.C. Chang, 2018

Licensee PAGEPress, Italy

Neurology International 2018; 10:7690

doi:10.4081/ni.2018.7690

received total laminectomy of $\mathrm{C} 3$ and $\mathrm{C} 6$, bilateral foraminotomy at $\mathrm{C} 4-5$ and $\mathrm{C} 5-6$, and partial laminectomy of $\mathrm{C} 4$ and $\mathrm{C} 5$. Despite the surgical operation, the patient's symptoms remained. During a visit to the rehabilitation department at 10 months after symptom onset, weakness of the upper and lower extremities was MRC $3+/ 5$ and $1 \sim 2 / 5$, respectively (Table 1 ). Tactile sensation was severely decreased in all extremities. She had suffered neuropathic pain in her extremities, and the numeric rating scale (NRS) score was 6 out of 10 . The pain was described as piercing and lancinating. In addition, she could not walk, thus she was ambulating using a wheelchair.

On the electrophysiological studies (Tables 2 and 3, Figure 2), the compound motor action potential (CMAP) showed a significantly increased motor distal latency and decreased motor conduction velocity and amplitude for both median and ulnar nerves with conduction block. CMAP on both peroneal and tibial nerves showed no response. The $\mathrm{F}$ wave on the left median nerve showed delayed latency, and that on the right median, bilateral ulnar, peroneal, and tibial nerves showed no response. Sensory nerve action potential (SNAP) on right ulnar nerves showed significantly increased peak latency and decreased 
amplitude, and that on the bilateral median, left ulnar, bilateral peroneal, and bilateral tibial nerves showed no response. On the EMG, positive sharp waves $(+3)$ were observed on all the evaluated muscles of the upper and lower extremities (deltoid, biceps brachii, flexor carpi radialis, abductor pollicis brevis, vastus medialis, tibialis anterior, and medial head of the gastrocnemius). Cerebrospinal fluid (CSF) analysis revealed a protein concentration of $240 \mathrm{mg} / \mathrm{dL}$ without any white blood cells. The patient was diagnosed with CIDP based on the criteria of the European Federation of Neurological
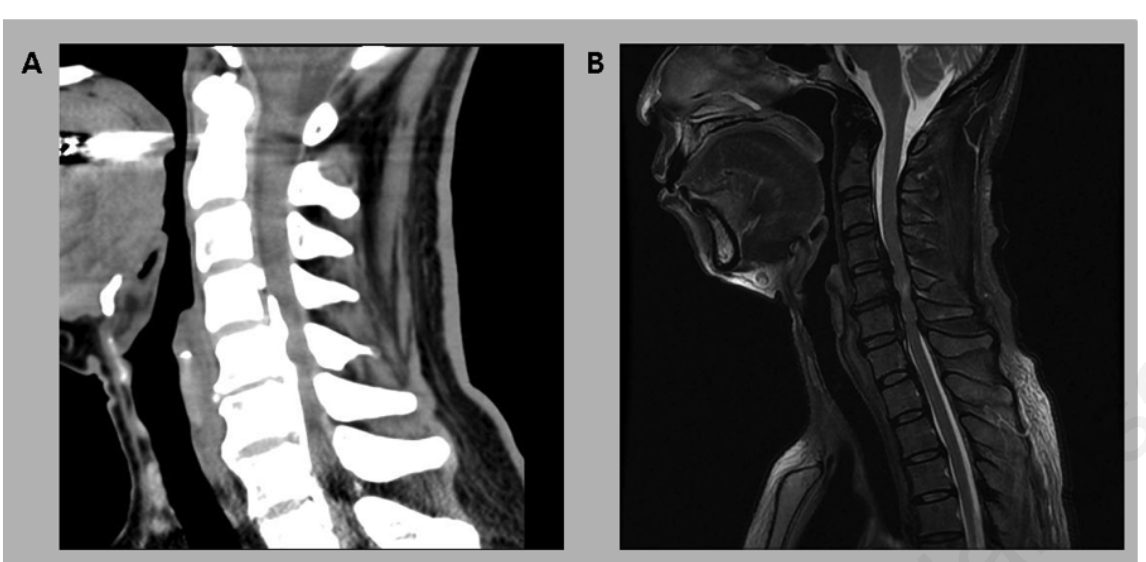

Figure 1. The sagittal CT (A) and T2-weighted cervical spine MRI (B) at 3 months after symptom onset showed ossification of the posterior longitudinal ligament at the level of C3-T1 with cervical cord compression and high signal intensity in the cervical spinal cord at the C5-6 disc space level.

Societies and the Peripheral Nerve Society. 10 The patient was treated with a 6week oral prednisolone regimen of $60 \mathrm{mg}$ each morning for 2 weeks, $40 \mathrm{mg}$ each morning for 1 week, $30 \mathrm{mg}$ each morning for 1 week, $20 \mathrm{mg}$ each morning for 1 week, and $10 \mathrm{mg}$ each morning for 1 week. Two months after finishing the regimen, the patient's motor power of the upper extremities was increased from $3+$ to 4 , and that of the lower extremities was increased from 1 2 to 3- (Table 1). In addition, her neuropathic pain nearly disappeared (NRS score: 1). and and peripheral nervous system (PNS) lesion induced by CIDP. Because NCS and EMG are pivot exams for diagnosing lesions in the PNS, they can be useful for ruling out

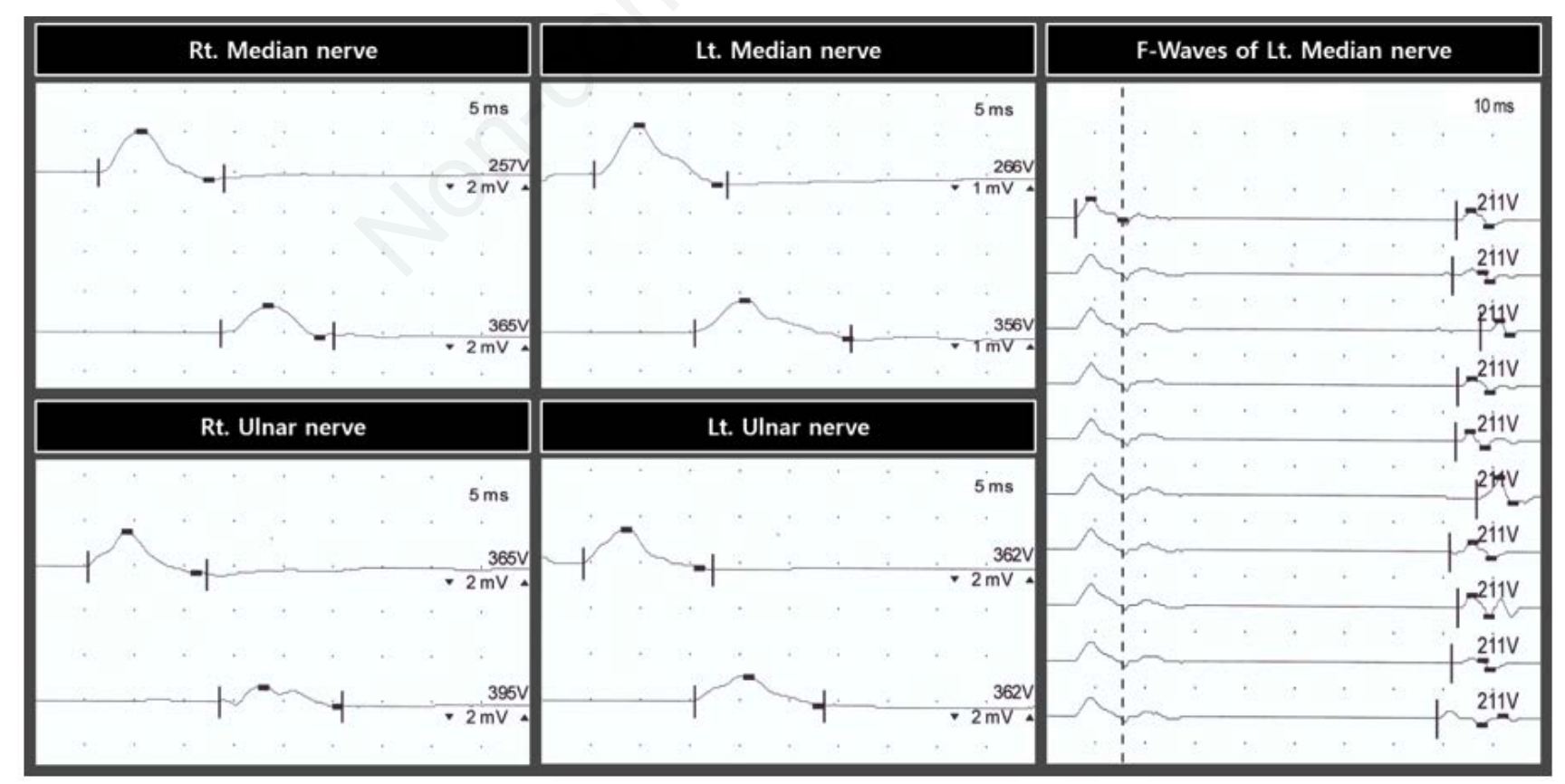

Figure 2. Median and ulnar motor nerve conduction responses at 10 months after onset showed delayed latency, decreased conduction velocity, and low amplitude of compound motor action potential. In addition, $F$ wave on the left median nerve showed delayed latency. 
Table 1. Changes in MRC scores in the patient.

\begin{tabular}{|c|c|c|c|}
\hline & $\begin{array}{l}2 \text { months after symptom onset } \\
\text { (pre-surgical operation) }\end{array}$ & $\begin{array}{l}10 \text { months after symptom onset } \\
\text { (post-surgical operation) }\end{array}$ & After oral prednisolone regimen \\
\hline Shoulder abductor & $4^{+}$ & $3+$ & 4 \\
\hline Elbow flexor & $4+$ & $3^{+}$ & 4 \\
\hline Finger flexor & $4^{+}$ & $3^{+}$ & 4 \\
\hline Hip flexor & $4^{+}$ & 2 & $3-$ \\
\hline Knee extensor & $4^{+}$ & 1 & $3-$ \\
\hline Ankle dorsiflexor & $4^{+}$ & 1 & $3-$ \\
\hline
\end{tabular}

MRC scores are as follows: 0 , no contraction; 1 , palpable contraction but no visible movement; 2 , movement without gravity; 3 , movement against gravity; 4 , movement against a resistance lower than the resistance overcome by the healthy side; 5 , movement against a resistance equal to the maximum resistance overcome by the healthy side.

Table 2. Results of the motor nerve conduction study.

\begin{tabular}{|c|c|c|c|}
\hline Nerve (normal values) & Results & Nerve (normal values) & Results \\
\hline $\begin{array}{l}\text { Rt. median } \\
\text { MNDL }(<4.2), \mathrm{ms} \\
\text { CMAP amp D/E }(>5.0), \mathrm{mV} \\
\text { Percentage of conduction block E-D } \\
\text { MNCV }(>50) \text {, ms } \\
\text { F-wave latency }(<30), \mathrm{ms}\end{array}$ & $\begin{array}{c}6.3 \\
2.5 / 1.6 \\
64 \\
18 \\
\text { No response }\end{array}$ & $\begin{array}{c}\text { Lt. median } \\
\text { MNDL }(<4.2), \mathrm{ms} \\
\text { CMAP amp D/E }(>5.0), \mathrm{mV} \\
\text { Percentage of conduction block E-D } \\
\text { MNCV }(>50), \text { ms } \\
\text { F-wave latency }(<30), \mathrm{ms}\end{array}$ & $\begin{array}{l}5.3 \\
1.5 / 1.0 \\
67 \\
21 \\
78.6\end{array}$ \\
\hline $\begin{array}{l}\text { Rt. ulnar } \\
\text { MNDL }(<4.2) \text {, ms } \\
\text { CMAP amp D/E }(>5.0), \mathrm{mV} \\
\text { Percentage of conduction block E-D } \\
\text { MNCV }(>50) \text {, ms } \\
\text { F-wave latency }(<30), \mathrm{ms}\end{array}$ & $\begin{array}{c}5.3 \\
1.9 / 1.0 \\
53 \\
17 \\
\text { No response }\end{array}$ & $\begin{array}{c}\text { Lt. ulnar } \\
\text { MNDL }(<4.2), \mathrm{ms} \\
\text { CMAP amp D/E }(>5.0), \mathrm{mV} \\
\text { Percentage of conduction block E-D } \\
\text { MNCV }(>50), \mathrm{ms} \\
\text { F-wave latency }(<30), \mathrm{ms}\end{array}$ & $\begin{array}{c}4.2 \\
1.8 / 1.3 \\
72 \\
21 \\
\text { No response }\end{array}$ \\
\hline Rt. peroneal & No response & Lt. peroneal & No response \\
\hline Rt. tibial & No response & Lt. tibial & No response \\
\hline
\end{tabular}

MNDL, motor nerve distal latency; CMAP, compound motor action potential; amp, amplitude; D, distal; E, elbow; E-D, elbow to distal segment; MNCV, motor nerve conduction velocity; BF, below fibular head; BF-D, below fibular head to distal segment; PF, popliteal fossa; PF-D, popliteal fossa to distal segment.

Table 3. Results of the sensory nerve conduction study.

\begin{tabular}{|c|c|c|c|}
\hline Nerve (Stimulation Site) (Normal Values) & Results & Nerve (Stimulation Site) (Normal Values) & Results \\
\hline $\begin{array}{l}\text { Rt. ulnar (wrist) } \\
\text { SNPL }(<3.6), \mathrm{ms} \\
\text { SNAP amp }(>20), \mu \mathrm{V}\end{array}$ & $\begin{array}{l}4 \\
4\end{array}$ & Lt. ulnar (wrist) & No response \\
\hline Rt, median (wrist) & No response & Lt. median (wrist) & No response \\
\hline Rt. superficial peroneal (lower leg) & No response & Lt. superficial peroneal (lower leg) & No response \\
\hline Rt. sural (lower leg) & No response & Lt. sural (lower leg) & No response \\
\hline
\end{tabular}

SNAL, sensory nerve action peak latency; SNAP, sensory nerve action potential; amp, amplitude.

other overlapped lesions in the PNS. In patients with a lesion in central nervous system (CNS), NCS and EMG are useful to evaluate the existence of combined lesions in the PNS in addition to lesions in the CNS.

CIDP is easily misdiagnosed because it is a relatively uncommon condition, and, in many cases, weakness or sensory deficits can be mild at the time of initial presentation of symptoms. ${ }^{12}$ However, the consequences of a missed or delayed diagnosis and delayed treatment can lead to a worse outcome and a long-term treatment with the potential for adverse effects. ${ }^{12}$ In our case, if the patient had received treatment earlier, the results and duration of the treatment may have been improved and shortened.

\section{Conclusions}

In conclusion, we describe here a case of missed diagnosis of CIDP, which is a peripheral polyneuropathy, in a patient who underwent surgery for a cervical spinal cord lesion due to OPLL. Our study shows that clinicians should consider the possibilities of another combined lesion in different areas even when patients have a definite lesion in the cervical spinal cord or cervical spine. Additionally, we recommend NCS/EMG to rule out other overlapped lesions in the PNS in patients who have a CNS lesion. This study is limited because it is a case study. Further studies that involve larger case numbers of missed diagnoses are warranted.

\section{References}

1. Koros C, Evangelopoulos ME, Kilidireas C, et al. Central nervous system demyelination in a Charcot-Marietooth type 1a patient. Case Rep Neurol 
Med 2013;2013:243652.

2. Mehndiratta MM, Gulati NS. Central and peripheral demyelination. $\mathrm{J}$ Neurosci Rural Pract 2014;5:84-6.

3. Tan JC, Burns DL, Jones HR. Severe ataxia, myelopathy, and peripheral neuropathy due to acquired copper deficiency in a patient with history of gastrectomy. JPEN J Parenter Enteral Nutr 2006;30:446-50.

4. Kim BS, Kim J, Koh HS, et al. Asymptomatic cervical or thoracic lesions in elderly patients who have undergone decompressive lumbar surgery for stenosis. Asian Spine J 2010;4:65-70.

5. Nakashima H, Yukawa Y, Suda K, et al. Abnormal findings on magnetic resonance images of the cervical spines in
1211 asymptomatic subjects. Spine (Phila Pa 1976) 2015;40:392-8.

6. Onizuka M, Suyama K, Shibayama A, et al. Asymptomatic brain tumor detected at brain check-up. Neurol Med Chir (Tokyo) 2001;41:431-4; discussion 435.

7. Seaman EK, Ross S, Sawczuk IS. High incidence of asymptomatic brain lesions in metastatic renal cell carcinoma. J Neurooncol 1995;23:253-6.

8. Chung T, Prasad K, Lloyd TE. Peripheral neuropathy: clinical and electrophysiological considerations. Neuroimaging Clin N Am 2014;24:4965.

9. Jang SH, Chang MC. Motor outcomes of patients with a complete middle cerebral artery territory infarct. Neural Regen Res 2013;8:1892-7.
10. Van den, Bergh PY, Hadden RD. European Federation of Neurological Societies; Peripheral Nerve Society. European Federation of Neurological Societies/Peripheral Nerve Society guideline on management of chronic inflammatory demyelinating polyradiculoneuropathy: report of a joint task force of the European Federation of Neurological Societies and the Peripheral Nerve Society: first revision. Eur J Neurol 2010;17:356-63.

11. Marchettini P, Lacerenza M, Mauri E, et al. Painful peripheral neuropathies. Curr Neuropharmacol 2006;4:175-81.

12. Gorson KC, Gooch CL. The (mis)diagnosis of CIDP: The high price of missing the mark. Neurology 2015;85:4889. 